\title{
High frequency of autoantibodies in patients with long duration type 1 diabetes
}

\author{
Carolyn C. Richardson • James A. Dromey • Kerry A. McLaughlin • \\ Diana Morgan • H. Jonathan Bodansky • Richard G. Feltbower • \\ Anthony H. Barnett • Geoffrey V. Gill • Steven C. Bain • Michael R. Christie
}

Received: 11 July 2013 / Accepted: 18 July 2013 /Published online: 20 August 2013

(C) Springer-Verlag Berlin Heidelberg 2013

Keywords Autoimmunity $\cdot$ GAD antibodies $\cdot$ HLA $\cdot$ IA-2 antibodies $\cdot$ Regeneration $\cdot$ Zinc transporter- 8 antibodies

\begin{abstract}
Abbreviations
GADA Antibodies to GAD

HLA Human leucocyte antigen

IA-2A Antibodies to insulinoma associated-2 protein

ZnT8A Antibodies to Zinc transporter-8
\end{abstract}

C. C. Richardson $\cdot$ K. A. McLaughlin $\cdot$ M. R. Christie $(\triangle)$

Diabetes Research Group, Division of Diabetes and Nutritional

Sciences, King's College London, Hodgkin Building,

Guy's Campus, SE1 1UL London, UK

e-mail: michael.christie@kcl.ac.uk

J. A. Dromey

Department of Medicine, King's College London, London, UK

J. A. Dromey

Murdoch Childrens Research Institute, Parkville, VIC, Australia

D. Morgan $\cdot$ H. J. Bodansky $\cdot$ R. G. Feltbower

Division of Epidemiology, University of Leeds, Leeds, UK

H. J. Bodansky

The Manny Cussins Diabetes Centre, St James's University Hospital, Leeds, UK

A. H. Barnett

Heart of England NHS Foundation Trust, Birmingham, UK

\section{A. H. Barnett $\cdot$ S. C. Bain}

Department of Endocrinology, Diabetes and Metabolism,

University of Birmingham, Birmingham, UK

G. V. Gill

Department of Diabetes and Endocrinology, University of Liverpool, Liverpool, UK

\section{S. C. Bain}

Institute of Life Science, Swansea University, Swansea, UK
To the Editor: It is apparent that small numbers of beta cells are able to survive in the type 1 diabetic pancreas for many years after clinical onset. Thus, insulin-positive islets have been observed in pancreases of patients with long-standing type 1 diabetes, with islets showing evidence of beta cell proliferation, apoptosis and T cell infiltration [1]. Circulating C-peptide was evident in the majority of Joslin Medalists who survived more than 50 years of diabetes, with age at disease onset and HLA genotype affecting the concentrations detected [2]. Post-mortem examination of pancreases from nine of these patients demonstrated residual beta cells in all individuals, with beta cell proliferation and $\mathrm{T}$ cell infiltration still being evident, even in those with undetectable serum $\mathrm{C}$-peptide [2]. Although signs of regeneration are not always seen in the diabetic pancreas, these observations suggest that beta cell turnover may occur long after diagnosis of type 1 diabetes, surviving beta cell mass being determined by relative rates of beta cell renewal and autoimmune beta cell destruction. Factors influencing persistence of autoimmunity in long-duration type 1 diabetes have not been widely investigated. In this study we determined the frequencies and levels of antibodies to the diabetes-associated islet autoantigens GAD (GADA), IA-2 (IA-2A) and zinc transporter-8 (ZnT8A) in patients with long-duration type 1 diabetes, and investigated the influence of age at diagnosis and HLA genotype on autoantibody persistence.

The 'Golden Years' project was established by Diabetes UK to investigate clinical features of patients with type 1 diabetes of more than 50 years duration [3]. Serum and DNA samples were collected with ethics approval and informed consent from 343 HLA-typed patients recruited into the Golden Years study, with mean age of 69.1 years (range 51-94), age at diagnosis of 14 (range 0-36 years) and duration of diabetes of 55 years (range 51-75 years). For comparison, sera were collected from 166 HLA-typed patients within 6 months of diagnosis of type 1 diabetes from clinics in 
London and Yorkshire with mean age of patients at diagnosis 17 years (range 0-37). GADA, IA-2A and ZnT8A (both $325 \operatorname{Trp}$ and $325 \mathrm{Arg}$ variants) were analysed by radioligand binding assay $[4,5]$, with autoantibody levels determined by comparison with dilution curves constructed using standard sera; those for GADA and IA-2A were calibrated against the WHO reference [6]. The performance of assays in the 2012 islet autoantibody standardisation workshop were as follows: GADA: $70 \%$ sensitivity, $96.7 \%$ specificity; IA-2A: $62.0 \%$ sensitivity, $100 \%$ specificity; ZnT8A: $62 \%$ sensitivity, $98.9 \%$ specificity (CCR, MRC, unpublished data). There was insufficient serum for ZnT8A analysis in ten Golden Years participants. Genotyping for HLA-DRB1 and $H L A-D Q B 1$ alleles was by PCR amplification using sequence-specific primers [7].

GADA, IA-2A and ZnT8A were detected in 76.5\%, 68.1\% and $54.8 \%$ of the recent onset type 1 diabetic patients, respectively. HLA associations of GADA and IA-2A in the recent onset sample were similar to those previously reported [8]; GADA was associated with $H L A-D R 3$, and IA-2A was positively associated with $H L A-D R 4$ and negatively associated with $H L A-D R 3$ in the absence of $D R 4$ (Table 1). The highest frequency of IA-2A was seen in the $0-12$ year age group. No associations between ZnT8A and age at onset or HLA were observed.
Of the long-standing diabetic patients, 197 (57\%) were positive for at least one of the three autoantibodies analysed. GADA were detected in $48.4 \%$ of these patients and the majority of the positive samples had GADA $>50$ WHO units $/ \mathrm{ml}$ (Table 1). GADA were detected at significantly higher frequency in patients $>18$ years of age at onset. Duration of diabetes did not affect GADA frequency (not shown). There was no evidence of an association of GADA with $H L A$ DR3. IA-2A and ZnT8A were detected at lower frequencies (5.8\% and $24.6 \%$, respectively) in the Golden Years cohort and almost all of the IA-2A positive samples were of low titre (Table 1). IA-2A maintained association with HLA-DR4, whereas ZnT8A were not associated with age at onset or HLA.

Autoantibodies have previously been shown to remain detectable in two thirds of patients during the 10 years after diabetes onset, and in some cases may increase in titre [9]. Our results now show a remarkable persistence of GADA in longterm survivors of type 1 diabetes, both in terms of autoantibody frequency and titre. IA-2A and ZnT8A were also present in patients with long-duration diabetes, but at lower frequency than GADA, and with reduced antibody levels. This may reflect weak expression of IA-2 and ZnT8 in surviving or regenerating islets in the diabetic pancreas when compared with GAD, or higher concentration requirements to sustain IA-2 and ZnT8 autoimmune responses. The characteristics of the GADA

Table 1 Frequencies and levels of islet autoantibodies in recent onset and long-standing diabetic patients and effect of age at onset and HLA genotype on autoantibody frequency

\begin{tabular}{|c|c|c|c|c|c|c|}
\hline & \multicolumn{2}{|l|}{ GADA } & \multicolumn{2}{|l|}{ IA-2A } & \multicolumn{2}{|l|}{ ZnT8A } \\
\hline & $<6$ months & $>50$ years & $<6$ months & $>50$ years & $<6$ months & $>50$ years \\
\hline Autoantibody frequency, $n(\%)$ & $127 / 166(76.5)$ & $166 / 343(48.4)$ & $113 / 166(68.1)$ & $20 / 343(5.8)$ & $91 / 166(54.8)$ & $82 / 333(24.6)$ \\
\hline \multicolumn{7}{|c|}{ Antibody levels of positive individuals ${ }^{\mathrm{a}}, \%$} \\
\hline$>100 \mathrm{U}$ & 59.9 & 34.9 & 66.4 & 0 & 16.5 & 0 \\
\hline $51-100 \mathrm{U}$ & 19.6 & 20.5 & 13.3 & 5.0 & 41.8 & 19.5 \\
\hline $21-50 \mathrm{U}$ & 14.1 & 30.7 & 5.3 & 10.0 & 30.8 & 40.2 \\
\hline$\leq 20 \mathrm{U}$ & 6.3 & 13.8 & 15.0 & 85.0 & 11.0 & 40.2 \\
\hline \multicolumn{7}{|l|}{ Effect of age at onset, $n(\%)$} \\
\hline 0-12 years & $27 / 37(73.0)$ & $73 / 162(45.1)$ & $30 / 37(81.1)$ & $10 / 162(6.2)$ & $22 / 37(59.5)$ & $36 / 157(22.9)$ \\
\hline $13-18$ years & $51 / 66(77.3)$ & 39/92 (42.4) & $43 / 66(65.2)$ & $7 / 92(7.6)$ & $40 / 66(60.6)$ & $22 / 88(25.0)$ \\
\hline$>18$ years & 49/63 (77.8) & $54 / 89(60.7)^{*}$ & $40 / 63(63.5)$ & $3 / 89(3.3)$ & $29 / 63(46.0)$ & $24 / 88(27.3)$ \\
\hline \multicolumn{7}{|l|}{ HLA genotypes, $n(\%)$} \\
\hline$D R 3 / 4$ & $45 / 52(86.5)^{*}$ & $79 / 150(52.7)$ & $40 / 52(76.9)$ & $10 / 150(6.67)$ & $27 / 52(51.9)$ & $36 / 144(25.0)$ \\
\hline DR4/non-3 & $40 / 58(69.0)$ & $53 / 114(46.5)$ & $41 / 58(70.7)$ & $9 / 114(7.9)$ & $32 / 58(55.2)$ & $31 / 110(28.2)$ \\
\hline$D R 3 /$ non-4 & $32 / 39(82.1)$ & 28/61 (45.9) & $21 / 39(53.8)^{*}$ & $1 / 61(1.6)$ & $21 / 39(53.8)$ & $11 / 61(18.0)$ \\
\hline Non- $D R 3 /$ non- $D R 4$ & $10 / 17(58.8)$ & 7/18 (38.9) & $11 / 17(64.7)$ & $0 / 18(0)$ & $11 / 17(64.7)$ & $4 / 18(22.2)$ \\
\hline \multicolumn{7}{|l|}{ HLA alleles, $n(\%)$} \\
\hline DR4 & $85 / 110(77.3)$ & $132 / 264(50.0)$ & $81 / 110(73.6)^{*}$ & $19 / 264(7.2)^{*}$ & $59 / 110(53.6)$ & $67 / 254(26.4)$ \\
\hline$D R 3$ & $77 / 91(84.6)^{* *}$ & $117 / 211(55.5)$ & $60 / 91(65.9)$ & $11 / 211(5.2)$ & 48/91 (52.7) & $47 / 205(22.9)$ \\
\hline
\end{tabular}

Associations of antibodies with age at onset and HLA within each patient group were tested by $\chi^{2}$ test: ${ }^{*} p<0.05 ;{ }^{* *} p<0.01$

${ }^{\mathrm{a}}$ units for GADA and IA2A are WHO units [6] 
response differed between patients with recent onset and longduration diabetes, with the latter showing stronger association with older age at onset and a loss of association with HLA-DR3. HLA requirements for GADA responses may change as the disease progresses, with 'high disease risk' HLA alleles being important for initial seroconversion [10], but less so as the response diversifies to new epitopes in established disease [8]. In contrast with the GADA response, the maintenance of an IA-2A response in long-duration diabetes appears highly dependent on HLA gene expression, with 19/20 IA-2A positive patients expressing HLA-DR4.

The Golden Years cohort is relatively protected from diabetic nephropathy and large vessel disease, and these patients require relatively low insulin doses [3]. The Joslin Medalists study has demonstrated residual insulin production and beta cell turnover, which may contribute to long-term survival of patients, but further islet renewal may be restricted by on-going islet inflammation and beta cell apoptosis [2]. The high frequency of islet autoantibodies detectable in long duration diabetes in our study is indicative of sustained immune responses to islet antigen in patients with long-standing diabetes, potentially stimulated by antigens from regenerating islets. If this is the case, then protocols developed to intervene in autoimmune responses to prevent type 1 diabetes may also benefit the established patient by helping restore beta cell function.

Acknowledgements We thank staff at clinical centres for assistance in patient recruitment and sample collection and patients for their participation in the study.

Funding This study was supported by grants from Diabetes UK. CCR was supported by a King's College London Health Schools Studentship.

Duality of interest The authors declare that there is no duality of interest associated with this manuscript.
Contribution statement $\mathrm{CCR}, \mathrm{JAD}, \mathrm{KAM}$ and $\mathrm{DM}$ acquired data. HJB, RGF, AHB, GVG, SCB and MRC designed the study. All authors contributed to the drafting, revision and approval of the manuscript.

\section{References}

1. Meier JJ, Bhushan A, Butler AE, Rizza RA, Butler PC (2005) Sustained beta cell apoptosis in patients with long-standing type 1 diabetes: indirect evidence for islet regeneration? Diabetologia 48:2221-2228

2. Keenan HA, Sun JK, Levine J et al (2010) Residual insulin production and pancreatic beta cell turnover after 50 years of diabetes: Joslin Medalist study. Diabetes 59:2846-2853

3. Bain SC, Gill GV, Dyer PH et al (2003) Characteristics of type 1 diabetes of over 50 years duration (the Golden Years Cohort). Diabet Med 20:808-811

4. Christie MR, Roll U, Payton MA, Hatfield ECI, Ziegler AG (1997) Validity of screening for individuals at risk for type 1 diabetes by combined analysis of antibodies to recombinant proteins. Diabetes Care 20:965-970

5. Wenzlau JM, Juhl K, Yu L et al (2007) The cation efflux transporter $\mathrm{ZnT} 8$ (Slc30A8) is a major autoantigen in human type 1 diabetes. Proc Natl Acad Sci U S A 104:17040-17045

6. Mire-Sluis AR, Gaines Das R, Lernmark $\AA$, Participants of the study (2000) The World Health Organization international collaborative study for islet cell antibodies. Diabetologia 43:1282-1292

7. Bunce M, O'Neill CM, Barnardo MC et al (1995) Phototyping: comprehensive DNA typing for HLA-A, B, C, DRB1, DRB3, DRB4, DRB5 \& DQB1 by PCR with 144 primer mixes utilizing sequence-specific primers (PCR-SSP). Tissue Antigens 46:355-367

8. Howson JMM, Stevens H, Smyth DJ et al (2011) Evidence that HLA class I and II associations with type 1 diabetes, autoantibodies to GAD and autoantibodies to IA-2, are distinct. Diabetes 60:2635-2644

9. Savola K, Sabbah E, Kulmala P, Vähäsalo P, Ilonen J, Knip M (1998) Autoantibodies associated with type 1 diabetes mellitus persist after diagnosis in children. Diabetologia 41:1293-1297

10. Ziegler A-G, Bonifacio E, BABYDIAB-BABYDIET Study Group (2012) Age-related islet autoantibody incidence in offspring of patients with type 1 diabetes. Diabetologia 55:1937-1943 